\title{
AN AUTOMATED METHOD FOR DETERMINATION OF ASCORBIC ACID IN URINE BY FLOW INJECTION CHEMILUMINESCENCE COUPLING WITH ON-LINE REMOVAL OF INTERFERENCE
}

\author{
LONGFEI CAI, CHUNXIU XU*
}

Department of Chemistry, Hanshan Normal University, Chaozhou, 521041, China.

(Received: May 9, 2011 - Accepted: September 13, 2011)

\begin{abstract}
A simple and automated method for determination of ascorbic acid (AA) in complex samples by flow injection chemiluminescence (FI-CL) was presented. It is based on the inhibitory effect of ascorbic acid on the chemiluminescence reaction between luminol and hydrogen peroxide in the flow system. A home-made micro column of cation exchange resin was adapted to the FI manifold to achieve on-line removal of interference. This method was used to determine the AA content in urine samples with a detection limit of $6.03 \times 10^{-9} \mathrm{~mol} / \mathrm{L}$ AA and recovery of $93.1-111.0 \%$. This proposed method allows high - throughput determination of AA in urine samples without chromatographic separation, demonstrating that the FI-CL method has significant potential in determination of species in complex samples by adapting a micro column filled with various functionalized materials to the FI manifold.
\end{abstract}

\section{INTRODUCTION}

Ascorbic acid, usually found in citrus fruits and vegetables, is mainly used as a cure for various diseases including scurvy, drug poisoning, liver disease and allergic reactions. Consequently, determination of ascorbic acid in foods, pharmaceuticals, and biological samples is crucial. A variety of methods have been employed for the determination of ascorbic acid in simple samples including foods, Vitamin $\mathrm{C}$ tablets and injections, among which iodometric method ${ }^{[1]}$ is the official method, while fluorimetry, ${ }^{2,3}$ atomic spectrometry, spectrophotometry ${ }^{5}$ and electroanalysis ${ }^{6,7}$ have also been reported.

For determination of AA in complex samples such as urine, various methods including spectrophotometry, ${ }^{8-11}$ electroanalysis ${ }^{12-14}$ and chromatography ${ }^{15,16}$ have been reported. Although spectrophotometric method is commonly used, it is limited by its time-consuming pretreatment process. Electroanalytical methods are sensitive in the determination of ascorbic acid in urine. However, many compounds in urine are capable of being adsorbed on electrodes, causing poisoning of electrodes surface. Chromatography is very effective for separation and determination of ascorbic acid in urine, but the high instrumental cost and low analytical speed limits its application.

Flow injection chemiluminescence (FI-CL) offers the advantages of simplicity of apparatus, high sensitivity, high analysis speed and good reproducibility for determination of ascorbic acid in simple samples including vitamin $\mathrm{C}$ injections, vitamin $\mathrm{C}$ tablets and foods, ${ }^{17-24}$ however, to the best of our knowledge, FI-CL have not been used for the determination of ascorbic acid in complex samples such as urine thus far due to the poor selectivity of chemiluminescent analysis and the complexity of urine samples. In this work, a simple and automated method was presented for determination of AA in urine samples by FI-CL coupling with a micro column of exchange resin. This method is based on the inhibitory effect of AA on oxidation reaction of luminol proceeded by hydrogen peroxide in $\mathrm{Na}_{2} \mathrm{CO}_{3}-\mathrm{NaHCO}_{3}$ medium. Anions didn't interfere with this $\mathrm{CL}$ reaction, while cations including $\mathrm{Pb}^{2+}, \mathrm{Mn}^{2+}, \mathrm{Cu}^{2+}$ and $\mathrm{Cr}^{3+}$ enhance the CL intensity. To remove the interference caused by these cations, a micro column of cation exchange resin was adapted to the flow system.

\section{EXPERIMENTAL}

\section{CHEMICALS AND REAGENTS}

All reagents were of analytical grade, the super-purified water was used throughout.

Hydrogen peroxide of $6 \times 10^{-2} \mathrm{~mol} / \mathrm{L}$ was prepared by dilution of $30 \%$ hydrogen peroxide (Tianjin Damao Chemical Factory, Tianjin, China).

Luminol stock solution of $0.01 \mathrm{~mol} / \mathrm{L}$ was prepared by dissolving $0.1770 \mathrm{~g}$ luminol (Nacalai Tesque, Inc., Kyoto, Japan) with $100 \mathrm{~mL}$ of $0.1 \mathrm{~mol} / \mathrm{L}$ sodium hydroxide. Luminol standard working solution of $8 \times 10^{-5} \mathrm{~mol} / \mathrm{L}$ was prepared by sequential dilution of stock solution with $0.1 \mathrm{~mol} / \mathrm{L} \mathrm{Na}_{2} \mathrm{CO}_{3}-0.1 \mathrm{~mol} / \mathrm{L}$ $\mathrm{NaHCO}_{3}$ solution

$\mathrm{AA}^{3}$ standard stock solution of $0.01 \mathrm{~mol} / \mathrm{L}$ was prepared by dissolving
$0.1760 \mathrm{~g}$ ascorbic acid (Tianjin chemical reagent factory, Tianjin, China) with $100 \mathrm{~mL}$ of water. The standard working solution of AA was prepared by sequential dilution of standard stock solution with water. The standard working solution of AA was prepared daily.

$0.1 \mathrm{~mol} / \mathrm{L} \mathrm{Na}_{2} \mathrm{CO}_{3}-0.1 \mathrm{~mol} / \mathrm{L} \mathrm{NaHCO}_{3}$ solution.

732 cation exchange resin was purchased from Guangdong Xilong Chemical Factory (Guangdong, China).

\section{APPARATUS}

The FI system, shown in Fig. 1, was a IFFM-E-FI-CL analysis system (Xi'an Remex Analytical instrument Co., Ltd., Xi'an, China) consisting of two peristaltic pumps (twelve-channel) and a sixteen-port injection valve with a sample loop $(50 \mu \mathrm{L})$ which were automatically operated by a computer equipped with software for control of the IFFM-E-FI-CL system. PTFE tubing $(0.8 \mathrm{~mm}$ i.d.) was used to connect all components of the flow system. The micro column $(30 \mathrm{~mm} \times 3.0 \mathrm{~mm})$ loading with $c a .0 .15 \mathrm{~g}$ cation exchange resin was made in laboratory and adapted to the carrier flow. The flow cell is a coiled glass tube so that there was a large surface area adjacent to the photomultiplier tube (PMT), the signal from the CL reaction was recorded by computer controlled by the software stated above. The New Human Power II water purification system (Human Corporation, South Korea) was used to produce the super-purified water.

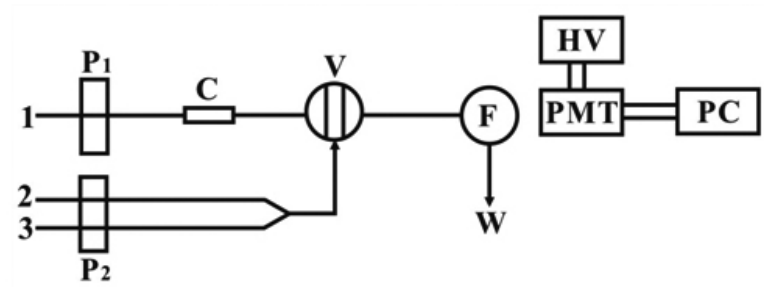

Fig.1. Schematic diagram of FI-CL analysis system coupling with cation exchange resin column. $\mathrm{P}$, peristaltic pump; $\mathrm{C}$, micro column of cation exchange resin; V, sampling inlet valve; F, flow cell; PMT, photomultiplier tube; $\mathrm{HV}$, negative high voltage; $\mathrm{PC}$, computer; $\mathrm{W}$, waste; 1 , sample solution or AA standard solution; 2, Hydrogen peroxide solution; 3, luminol solution.

\section{PROCEDURE}

The sample or AA standard solution was continuously pumped by pump 1 at a flow rate of $1.5 \mathrm{~mL} / \mathrm{min}$, while hydrogen peroxide and luminol solutions were pumped and merged by pump 2 at a flow rate of $1.0 \mathrm{~mL} / \mathrm{min}$. The mixture of luminol and hydrogen peroxide was injected into the sample stream using a $50 \mu \mathrm{L}$ sample loop. The mixture of sample or AA standard solution, hydrogen peroxide and luminol were then pumped to the flow cell by pump 1 at a flow rate of $1.5 \mathrm{~mL} / \mathrm{min}$. The light emitted was detected by PMT with no wavelength discrimination. The PMT window was automatically opened once the FI-CL system began to work. The concentration of ascorbic acid was quantified by 
measuring the logarithm of $\mathrm{I}_{0} / \mathrm{I}_{t}$, where $\mathrm{I}_{0}$ and $\mathrm{I}_{\mathrm{t}}$ were $\mathrm{CL}$ signals in the absence and presence of ascorbic acid, respectively.

\section{RESULTS AND DISCUSSION}

\section{INHIBITION OF ASCORBIC ACID ON CL REACTION}

The inhibitory effect of AA on CL intensity was investigated using $6 \times 10^{-}$ $2 \mathrm{~mol} / \mathrm{L} \mathrm{H}_{2} \mathrm{O}_{2}, 8 \times 10^{-5} \mathrm{~mol} / \mathrm{L}$ luminol and three AA solutions with varying concentrations. As figure 2 shows, AA could inhibit the CL reaction between luminol and hydrogen peroxide significantly. Several luminol-oxidant CL system $^{20,22,23,25,26}$ have been employed for the determination of AA by FI-CL based on inhibitory effects of AA. In those systems reported previously, the concentration of AA and oxidants was in the same level. AA reacts with the oxidants such that the concentration of oxidants reacting with CL reagent decreased, demonstrating inhibitory effect on CL intensity. However, in this work, concentration of oxidant is much higher than that of AA, therefore the amount of oxidant reacting with AA was negligible. We suppose, therefore, in this work, ascorbic acid is a catalyst inhibiting CL reaction rather than just a reducing reagent reacting with oxidants although the catalytic mechanism of ascorbic acid is unclear.

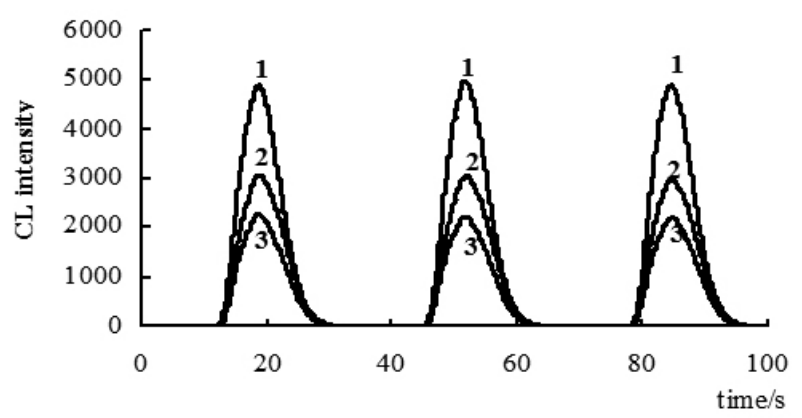

Fig.2 Inhibitory effect of AA on CL reaction obtained by three successive injections of hydrogen peroxide and luminol into AA solutions with different concentrations. 1, ascorbic acid solution $(0 \mathrm{~mol} / \mathrm{L}) ; 2$, ascorbic acid solution $\left(2.0 \times 10^{-7} \mathrm{~mol} / \mathrm{L}\right) ; 3$, ascorbic acid solution $\left(4.0 \times 10^{-7} \mathrm{~mol} / \mathrm{L}\right)$. Conditions: luminol, $8 \times 10^{-5} \mathrm{~mol} / \mathrm{L}\left(0.1 \mathrm{~mol} / \mathrm{L} \mathrm{Na}_{2} \mathrm{CO}_{3}-0.1 \mathrm{~mol} / \mathrm{L} \mathrm{NaHCO}\right.$ medium $) ; \mathrm{H}_{2} \mathrm{O}_{2}$, $6 \times 10^{-2} \mathrm{~mol} / \mathrm{L}$.

\section{EFFECT OF $\mathrm{H}_{2} \mathrm{O}_{2}$ CONCENTRATION}

The Effect of $\mathrm{H}_{2} \mathrm{O}_{2}$ concentration on CL intensity and inhibitory effect of ascorbic acid were investigated. The logarithm of $\mathrm{I}_{0} / \mathrm{I}_{\mathrm{t}}$ versus $\mathrm{H}_{2} \mathrm{O}_{2}$ concentration was plotted. As shown in Fig.3, a constant inhibitory effect of ascorbic acid was obtained until $0.06 \mathrm{~mol} / \mathrm{L}$. Therefore, $\mathrm{H}_{2} \mathrm{O}_{2}$ of $0.06 \mathrm{~mol} / \mathrm{L}$ was chosen for the analytical procedure.

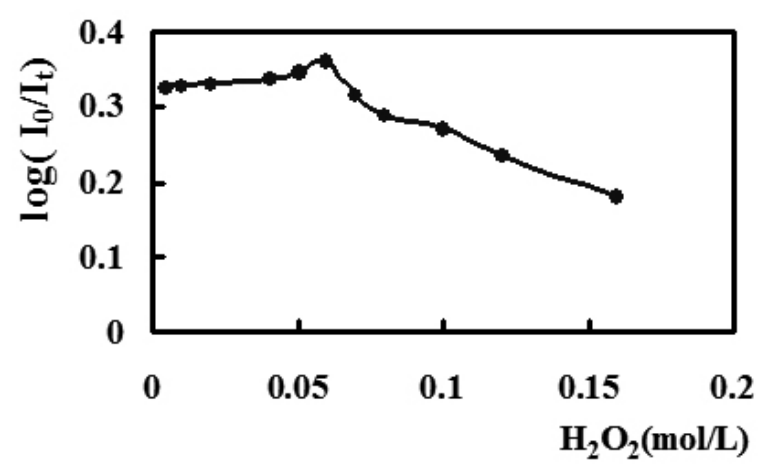

Fig.3 Effect of $\mathrm{H}_{2} \mathrm{O}_{2}$ concentration. Luminol, $8 \times 10^{-5} \mathrm{~mol} / \mathrm{L}(0.1 \mathrm{~mol} / \mathrm{L}$ $\mathrm{Na}_{2} \mathrm{CO}_{3}-0.1 \mathrm{~mol} / \mathrm{L} \mathrm{NaHCO}$ medium.

\section{EFFECT OF LUMINOL CONCENTRATION}

The effect of luminol concentration on inhibitory effect of AA was investigated. As shown in Fig. 4, inhibitory effect of AA was significant when luminol concentration was less than $1.0 \times 10^{-4} \mathrm{~mol} / \mathrm{L}$, the greatest inhibitory effect was obtained when luminol concentration was $8 \times 10^{-5} \mathrm{~mol} / \mathrm{L}$. Therefore, luminol solution of $8 \times 10^{-5} \mathrm{~mol} / \mathrm{L}$ was chosen for the analytical procedure.

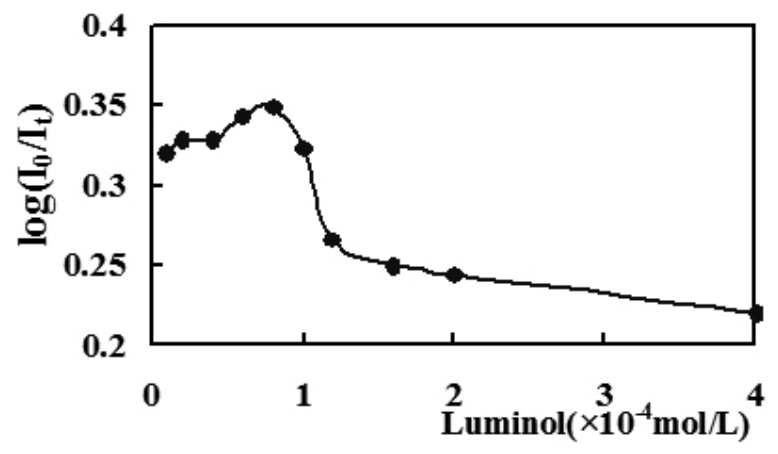

Fig.4 Effect of luminol concentration. $\mathrm{H}_{2} \mathrm{O}_{2}(0.06 \mathrm{~mol} / \mathrm{L})$; other conditions were the same as that in figure 3 .

\section{EFFECT OF SAMPLE ACIDITY}

The acidity of sample solution poses significant effect on both CL intensity and the inhibitory effect of AA. Neither significant CL intensity nor inhibitory effect was obtained when the sample have strong acidity. However, when $\mathrm{pH}$ of sample solution was in the range of 6.5-9.8, both CL intensity and inhibitory effect of AA were significant. At $\mathrm{pH}$ higher than 9.8, the inhibitory effect of AA decreased rapidly with the increasing $\mathrm{pH}$ although $\mathrm{CL}$ signal was still significant. Therefore, $\mathrm{H}_{2} \mathrm{O}$ was chosen as the medium of sample solution for the analytical procedure since ascorbic acid was unstable in alkaline conditions.

ANALYTICAL PERFORMANCE

The linear relationship between the logarithm of $\left(\mathrm{I}_{0} / \mathrm{I}\right)$ and AA concentration was studied under the optimum conditions stated above. As shown in Fig. 5, perfect linear relationship was obtained between the value of $\log \left(\mathrm{I}_{0} / \mathrm{I}_{\mathrm{t}}\right)$ and AA concentration when the concentration of AA was in the range of $2 \times 10^{-8}-6 \times 10^{-7} \mathrm{~mol} / \mathrm{L}$. The regression equation was $\log \left(\mathrm{I}_{0} / \mathrm{I}\right)=0.0774 c\left(\times 10^{-7}\right.$ $\mathrm{mol} / \mathrm{L})+0.0298$ with correlation coefficient of 0.997 . The relative standard deviation (RSD) obtained by determining $3.0 \times 10^{-8} \mathrm{~mol} / \mathrm{L}$ ascorbic acid 11 times was $6.7 \%$, demonstrating a good reproducibility for determination of AA. The detection limit, based on the $3 \mathrm{Sb}$ criterion ( $\mathrm{Sb}$ is the concentration corresponding to the standard deviation obtained from determining $3.0 \times 10^{-8}$ $\mathrm{mol} / \mathrm{L}$ AA solution 11 times), was $6.03 \times 10^{-9} \mathrm{~mol} / \mathrm{L}$ for ascorbic acid.

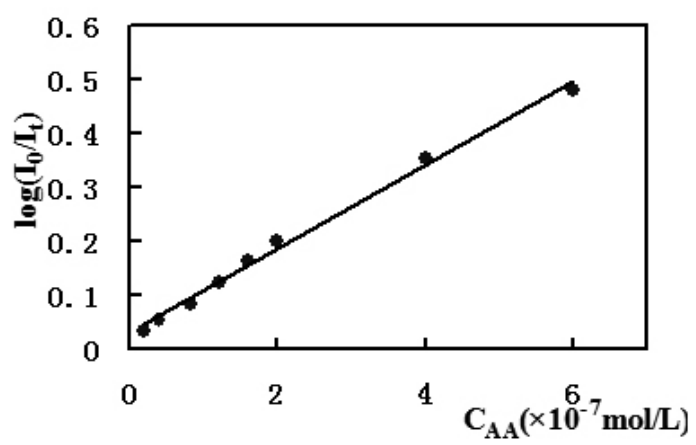

Fig.5 The plot of $\log \left(\mathrm{I}_{0} / \mathrm{I}\right)$ versus AA concentration. Other conditions were the same as that in Fig. 3.

\section{EFFECT OF FOREIGN SPECIES}

The effect of foreign species on the determination of $4.0 \times 10^{-7} \mathrm{~mol} / \mathrm{L}$ AA was studied. Foreign specie was considered not to interfere with the determination of AA when the error caused by the foreign specie was within $\pm 5 \%$. For the FI-CL system without adapting micro column of cation exchange resin, the tolerant ratios were as follows: 10000 for $\mathrm{Na}^{+}, \mathrm{Zn}^{2+}, \mathrm{K}^{+}, \mathrm{Li}^{+}, \mathrm{NH}_{4}^{+}$, $\mathrm{NO}_{3}^{-}, \mathrm{SO}_{3}^{2-}, \mathrm{NO}_{2}^{-}, \mathrm{Cl}^{-}, \mathrm{PO}_{4}^{3-}, \mathrm{SO}_{4}^{2-}$, uric acid, 1000 for $\mathrm{Mg}^{2+}, \mathrm{Ca}^{2+}, \mathrm{Al}^{3+}, \mathrm{Ba}^{2+}$, $\mathrm{Sr}^{2+}, \mathrm{Cd}^{2+}, \mathrm{I}, \mathrm{ClO}_{3}^{-}$, citrate, borate, starch, oxalate, tartrate, 100 for $\mathrm{Co}^{2+}, \mathrm{Fe}^{2+}$, $\mathrm{Fe}^{3+}, \mathrm{Sb}^{3+}, \mathrm{Sn}^{2+}$, glucose, glycin, L-glutamic acid, gelatin, arginine, 10 for $\mathrm{Pb}^{2+}$, $\mathrm{Mn}^{2+}$. Equal amount of $\mathrm{Cu}^{2+}, \mathrm{Cr}^{3+}$ enhanced the $\mathrm{CL}$ signal. The tolerant ratios for $\mathrm{Pb}^{2+}, \mathrm{Mn}^{2+}, \mathrm{Cu}^{2+}$ and $\mathrm{Cr}^{3+}$ were above 1000 after a micro column of cation exchange resin was adapted to the flow system.

\section{ANALYTICAL APPLICATIONS}

A micro column $(30 \mathrm{~mm} \times 3.0 \mathrm{~mm})$ of cation exchange resin was adapted to the flow system, as shown in Figure 1. Urine samples of 4 apparently healthy 
volunteers were collected and diluted appropriately with water, ascorbic acid in these samples was then determined as the procedure stated above. The results were as shown in table 1.

Tabla.1 Analytical results of ascorbic acid in human urine.

\begin{tabular}{|c|c|c|c|c|}
\hline $\begin{array}{c}\text { Sample } \\
\text { No. }\end{array}$ & $\begin{array}{c}\text { Found } \\
(\mathrm{mg} / \mathrm{L})\end{array}$ & $\begin{array}{c}\text { Added } \\
(\mathrm{mg} / \mathrm{L})\end{array}$ & $\begin{array}{c}\text { Found } \\
(\mathrm{mg} / \mathrm{L})\end{array}$ & Recovery(\%) \\
\hline 1 & 126.24 & 100 & 236.28 & 110.0 \\
\hline 2 & 172.39 & 100 & 269.53 & 97.1 \\
\hline 3 & 89.52 & 100 & 200.33 & 111.0 \\
\hline 4 & 145.31 & 100 & 249.72 & 104.4 \\
\hline $5^{\text {a }}$ & 375.16 & 100 & 468.25 & 93.1 \\
\hline
\end{tabular}

a. sample collected from a volunteer(No.
taking $420 \mathrm{mg}$ vitamin $\mathrm{C}$ tablets(Vitamin C tablet 1 ).

\section{CONCLUSIONS}

FI-CL is characterized by the high sensitivity, low sample/reagent consumption, simplicity of apparatus and high throughput. Although FI-CL is considered as not suitable for analysis of complex samples owing to the poor selectivity of $\mathrm{CL}$ analysis, we presented a method for determination of AA in urine by FI-CL coupling with a micro column of cation exchange resin. Comparing with other FI-CL method for determination of ascorbic acid, this method could be employed for determination of ascorbic acid in complex samples without chromatographic separation. This method demonstrates that FI-CL could be used for analysis of complex samples by adapting a pretreatment column to the FI manifold. Additionally, various functionalized materials including the molecular imprinted polymer (MIP) could be filled into the micro column for various analytical purposes.

\section{ACKNOWLEDGEMENTS}

This work was supported by the youth scientific fund of Hanshan Normal University (Grants 413611, 413615), doctor start-up fund of Hanshan Normal University (Grant QD201106) and Guangdong Provincial Natural Science Foundation of China (Grant S2011040002246).

\section{REFERENCES}

1. Editorial Committee of the Pharmacopoeia of People's Republic of China. 1995. The pharm acopoeia of People's Republic of China: Part. Beijing : Chemistry Industry Press.

2. J. H. Yang, Q. L. Ma, F. Huang, L. M. Sun, J. Dong, Anal. Letts., 31, 2757, (1998).

3. Q. L. Wang, Z. H. Liu, L. Y. Mao, R. X. Cai, Chin. J. Anal. Chem., 28, $1229,(2000)$

4. M. C. Yebra, R. M. Cespón, A. Moreno-Cid, Anal. Chim. Acta., 448, 157, (2001).

5. Z. X. Zhang, D. M. Sun, Z. H. Rong, Spectrosc. Spec. Anal., 24, 873, (2004).

6. S. S. L. Castro, V. R. Balbo, P. J. S. Barbeira, N. R. Stradiotto, Talanta, 55, 249, (2001).

7. X. M. Wu, J. Wu, Y. H. Zou, G. L. Shen, R. Q. Yu, J. Anal. Sci., 21, 359, (2005).

8. A. Ruiz Medina, M. L. Fernaóndez de Córdova, A. Molina Dóa. $J$. Pharmaceut. Biomed., 20, 247, (1999).

9. P. Ortega Barrales, M. L. Fernaóndez de Córdova, A. Molina Dóa, Anal. Chim. Acta., 360, 143, (1998).

10. T. Kleszczewski, E. Kleszczewska, J. Pharmaceut. Biomed., 29, 755, (2002).

11. A. Molina Dóaz, I. Ortega Carmona, M. I. Pascual Reguer, Talanta, 47, 531, (1998).

12. R. C. Matos, M. A. Augell, C. L. Lago, L. Angnes, Anal. Chim. Acta., 404, $151,(2000)$

13. T. R. L. C. Paixao, M Bertotti, J. Pharmaceut. Biomed., 46, 528, (2008).

14. E. M. Strochkova, Y. I. Tur'flyan, I. Kuselman, A. Shenhar, Talanta, 44 , 1923, (1997).

15. I. Koshiishi, T Imanari, Anal. Chem., 69, 216, (1997).

16. W. D. Mason, E. N. Amick, W. Heft, Anal. Letts., 13, 817, (1980).

17. Y. H. Li, J. R. Lv, J. Shaanxi Normal Univ. (Nat. Sci. Ed.), 29, 81, (2001).

18. Y. J. Ma, M. Zhou, X. Y. Jin, B. Z. Zhang, H. Chen, N. Y. Guo, Anal.
Chim. Acta., 464, 289, (2002).

19. C. G. Xie, C. F. Liu, W. G. Chang, H. F. Li, Chin. J. Spectro. Lab., 21, 439, (2004).

20. F. Li, W. Y. Zhang, G. Y. Zhu, Chin. J. Anal. Chem., 28, 1523, (2000).

21. N. Anastos, N. W. Barnett, B. J. Hindsonl, C. E. Lenehan, S. W. Lewis, Talanta, 64, 130, (2004).

22. Y. X. Zhou, T. Nagaoka, F. Li, G. Y. Zhu, Talanta, 48, 461, (1999).

23. H. H. Chen, Q. Wei, Z. J. Zhang, Chin. J. Anal. Chem., 25, 1079, (1997).

24. D. Y. He, S. H. He, Z. J. Zhang, Anal. Letts., 40, 2935, (2007).

25. F. C. Wang, W. Qin, Z. J. Zhang, Chin. J. Anal. Chem., 25, 1255, (1997).

26. W. P. Yang, B. L. Li, Z. J. Zhang, G. H. Tian, Chin. J. Anal. Chem., 24, 579, (1996). 